\title{
Binding promises and cooperation among strangers*
}

\author{
Gabriele Camera ${ }^{1}$ \\ University of Basel \\ and \\ Chapman University
}

\author{
Marco Casari \\ University of Bologna \\ Maria Bigoni
University of Bologna \\ Maria Bigoni
University of Bologna
}

\section{November 2012}

\begin{abstract}
In an experiment, a group of strangers was randomly divided in pairs to play a prisoners' dilemma; this process was indefinitely repeated. Cooperation did not increase when subjects could send public messages amounting to binding promises of future play.
\end{abstract}

Keywords: coordination, cheap-talk, deception, repeated game, social norms.

JEL codes: C90, C70, D80

\footnotetext{
${ }^{*}$ We thank an anonymous referee for helpful suggestions. Camera thanks the NSF for research support through the grant CCF-1101627. Financial support for the experiments was also partially provided by a grant from Purdue's CIBER and Einaudi Institute for Economics and Finance.

${ }^{1}$ Corresponding author: Gabriele Camera, Faculty of Business and Economics, Department of Macroeconomics, University of Basel, Peter Merian-Weg 6, CH - 4002 Basel, Switzerland. Tel: +41 (0)61 267 2458. e-mail: gabriele.camera@unibas.ch
} 


\section{Introduction}

Non-binding pre-play communication has been shown to promote welfare in some experiments on social dilemmas (Ostrom et al., 1992) but not in others (Wilson and Sell, 1997, Duffy and Feltovich, 2006). Such ineffectiveness may stem from shortcomings in communication, such as deception or lack of credibility of messages (Aumann 1990, Farrell and Rabin, 1996). Indeed, Wilson and Sell (1997) explicitly conjecture that communication would be more effective if promises could be binding. This paper tests such hypothesis by considering two questions: Would subjects in an experiment take steps to address such communication shortcomings? And if so, would such enhanced communication foster trust and be more effective?

We consider interactions among strangers, where there truly is a need of communication and coordination to achieve cooperation. In a Baseline treatment, subjects were assigned to a group of four members; in every period they were randomly divided into pairs to play a prisoners' dilemma (PD). Subjects could observe average group cooperation but not individual histories. Group interaction was indefinitely repeated; hence, multiple equilibria were possible, including the efficient outcome. In the Pledge treatment, subjects could send a message to the entire group, before playing the PD game; they could also audit messages, i.e., sanction all those group members whose actions and messages differed. Messages could thus represent pledges, i.e., binding promises of future play.

The data reveal that subjects sought to solve deception problems in communication: auditing took place in almost half of the periods, while pledges were rarely breached. However, cooperative behavior in Pledge did not increase relative to Baseline but rather declined. Pledging cooperation made cooperators easy prey for defectors which led to a collapse of communication and trust. This suggests that the possibility of sending messages amounting to binding promises 
is not sufficient to make communication effective in sustaining cooperation and, in fact, can backfire.

\section{Experimental Design}

The stage game was the PD in Table 1, where $Y=$ cooperate and $Z=$ defect.

\begin{tabular}{ccc}
\hline & $Y$ & $Z$ \\
\hline$Y$ & 25,25 & 5,30 \\
$Z$ & 30,5 & 10,10 \\
\hline
\end{tabular}

Table 1: Payoffs

Each session involved twenty subjects and five supergames consisting of an indefinite sequence of periods achieved by a random continuation rule (Roth and Murnighan, 1978). At the end of each period, the computer drew an integer between 1 and 100 from a uniform distribution, and showed it to all participants. The supergame terminated simultaneously for all with a draw of 96 or higher. Hence, in each period the supergame was expected to continue for 19 additional periods.

We built twenty-five economies in each session by creating five groups per supergame. In each period subjects interacted only with members of their group, in randomly formed pairs. Subjects could not identify opponents, hence could not use reputational mechanisms; they could observe their payoff, the group's average cooperation rate, but not individual histories. No two participants ever interacted together for more than one supergame.

This design admits multiple equilibria, ranging from full defection to the efficient outcome. Given that monitoring was public, the efficient outcome can be sustained as a sequential equilibrium for all discount factors above 0.25 when everyone adopts the following strategy: 
start cooperating and keep cooperating unless someone defects, in which case defect forever. ${ }^{1}$ This follows from the Folk Theorem-type results in Kandori (1992) and Ellison (1994).

Stage game, continuation probability, and matching protocols were identical across treatments. In the Pledge treatment, there was a communication stage before period one, and then every four periods. Communication was structured, public, costless, and anonymous. Subjects could send all group members a three-part message, consisting of a suggestion $\mathrm{Y}, \mathrm{Z}$, or "not sure"(i) for the subject, (i) for her anonymous match, and (iii) for everyone else. Here, we focus on part (i), which could be used to signal intentions of play. We identify $\mathrm{Y}$ and $\mathrm{Z}$ as explicit messages because the message-action mapping is clear, and "not sure" as neutral.

Messages could be transformed into something that amounted to binding promises: subjects could pay one point to "audit." If at least one subject audited, ten points were deducted from all group members (auditor included) who sent an explicit message in the last communication round, but did not choose the corresponding action in the period; selecting "not sure" protected from sanctions. The number of sanctioned subjects was made public.

We recruited 80 subjects through e-mail and in-class-announcements. Sessions were run at Purdue University. No eye contact was possible among subjects. Instructions were read aloud with copies on all desks. Average earnings were $\$ 27.28$ (no show-up fee). Sessions comprised on average 102 periods, and lasted about 3 hours, including instruction reading and a quiz. ${ }^{2}$

In comparison to the Baseline, communication in Pledge: (1) maintains the multiplicity of equilibria, because subjects could simply ignore messages, and (2) maintains anonymity because individual histories, approval or disapproval, or explicit threats could not be conveyed. Hence,

\footnotetext{
${ }^{1}$ For a proof and further details see the anonymous public monitoring treatment in Camera and Casari (2009).

${ }^{2}$ Session dates: 27.4.05, 1.9.05 (Baseline, also analyzed in Camera and Casari, 2009), 5.4.07, 11.4.07 (Pledge). Exchange rate: $\$ .13$ for every 10 points.
} 
even if actions $Y$ and $Z$ are both part of a sequential equilibrium, messages are not necessarily credible (Farrell and Rabin, 1996). ${ }^{3}$

Auditing could eliminate deception because the sender of an explicit message had incentives to behave accordingly. Yet, auditing cannot sustain the efficient outcome per se because it is costly, and in a cooperative equilibrium there is no reason to audit.

Three elements differentiate this design from previous studies. First, there exists a continuum of equilibria, including the Pareto efficient outcome, while in experimental studies of deception in finitely repeated social dilemmas defection is the unique equilibrium. Second, subjects could send explicit or neutral messages, which helps in detecting and quantifying deception. Third, auditing allows us to assess whether or not a mechanism to remove deception emerges endogenously.

\section{Results}

Result 1: A mechanism to enhance the credibility of communication emerged endogenously.

Auditing took place in $44.6 \%$ of the periods, which enhanced the credibility of messages and transformed explicit messages into credible pledges. Messages largely reflected truthful intentions-pledges were breached only $5.6 \%$ of the times-and were perceived as truthful: subjects cooperated more when they saw more Y messages. Those who signaled a cooperative intention were more likely to cooperate even when no one else manifested a similar intention, but all subjects tended to cooperate more when observing more Y messages (Table 4).

\footnotetext{
${ }^{3}$ E.g., a subject who is playing "always defect" may send a message $Y$ to induce cooperation. That is to say, structured messages are not necessarily self-signaling and self-committing and can be outright deceptive.
} 


\begin{tabular}{lccc}
\hline & \multicolumn{2}{c}{ Cooperative messages (Y)sent by others in the group } \\
Message sent by a subject & 0 & 1 & 2 or 3 \\
& & & $39.8 \%$ \\
\hline Not sure & $20.6 \%$ & $(853)$ & $(420)$ \\
& $(680)$ & $81.9 \%$ & $96.9 \%$ \\
$Y$ & $71.4 \%$ & $(386)$ & $(288)$ \\
& $(301)$ & & $5.9 \%$ \\
$Z$ & $2.9 \%$ & $4.0 \%$ & $(34)$ \\
\hline
\end{tabular}

Table 4: Frequency of cooperation in Pledge

Notes: One observation per subject, per period (total number in parentheses).

A probit regression (supporting materials) confirms that explicit messages amounted to binding promises and were used to facilitate cooperation.

One would expect that the possibility to sanction untruthful messages would foster cooperation, not only because messages amounted to binding promises, but also given previous results on costly personal punishment. We find that structured, repeated communication opportunities did not foster cooperation even if it is part of a Nash equilibrium.

\begin{tabular}{lccc}
\hline & $\begin{array}{c}\text { Avg. cooperation rate } \\
\text { (all periods) }\end{array}$ & $\begin{array}{c}\text { Avg. cooperation rate } \\
\text { (period 1) }\end{array}$ & $\begin{array}{c}\text { Avg. coordination on } \\
\text { cooperation }\end{array}$ \\
\hline Baseline & $58.6 \%$ & $70.5 \%$ & $28.6 \%$ \\
Pledge & $57.7 \%$ & $65.0 \%$ & $17.4 \%$ \\
\hline
\end{tabular}

Table 2: Cooperation by treatment

Result 2: In the Pledge treatment, average cooperation did not increase, while average coordination on cooperation fell. 
The cooperation rate is the fraction of $\mathrm{Y}$ actions in the group, in a supergame. Coordination on cooperation is the fraction of periods in a supergame in which everyone in a group cooperated. ${ }^{4}$ Considering all periods, average cooperation rates in Baseline are not significantly lower than Pledge. A statistical test does not reject the null hypothesis that observations from the two treatments are drawn from the same population (Mann-Whitney tests, $n 1=n 2=50$, $\mathrm{p}$-value $>0.10$ ). ${ }^{5}$ The difference in period 1 cooperation across treatments is not statistically significant (MannWhitney test, $\mathrm{n} 1=\mathrm{n} 2=50, \mathrm{p}$-value $>0.10$ ). Only in the first supergame, cooperation rates are lower in Baseline than in Pledge (Tobit regression, all periods) but this result is not robust to including all supergames. However, the availability of structured communication significantly reduces coordination on cooperation with respect to the Baseline (Mann-Whitney pairwise tests, $\mathrm{n} 1=\mathrm{n} 2=50, \mathrm{p}$-value $=0.076)$. A Tobit regression confirms this result (supporting materials).

Communication was ineffective in facilitating efficient Nash play. The reason was not deception (Result 1) and cannot be entirely attributed to limitations in the message space. Instead, the transformation of cheap talk into something akin to binding messages created a holdup problem, which ultimately reduced the usefulness of communication as a way to coordinate on efficient Nash play. The widespread use of auditing did not aim at building trust, but at extracting rents from cooperators, which reduced trust.

Result 3: Defectors audited more often than cooperators.

\footnotetext{
${ }^{4}$ Unless otherwise specified, the unit of observation is the group in a supergame (50 observations per treatment).

${ }^{5}$ The results of statistical tests rely on assuming that all observations are independent. All tests are two-sided.
} 
Auditing exposed those who pledged cooperation to the risk of becoming prey of opportunistic subjects, who sent neutral messages, defected and also audited to ensure compliance. Cooperators who sent a Y message made $33.9 \%$ of all auditing requests; defectors who sent a neutral message made $46.2 \%$ of all auditing requests (Table 7 ). Through auditing, defectors could "hold up" cooperators for the next four periods.

\begin{tabular}{cccccc}
\hline & & Message sent & & Total & $N$ \\
Action & Not sure & $\mathrm{Y}$ & $\mathrm{Z}$ & & \\
\hline $\mathrm{Y}$ & $11.1 \%$ & $33.9 \%$ & $0.2 \%$ & $\mathbf{4 5 . 3} \%$ & 191 \\
$\mathrm{Z}$ & $46.2 \%$ & $4.0 \%$ & $4.5 \%$ & $\mathbf{5 4 . 7} \%$ & 231 \\
Total & $57.3 \%$ & $37.9 \%$ & $4.7 \%$ & $\mathbf{1 0 0 . 0} \%$ & 422 \\
$N$ & 242 & 160 & 20 & 422 & \\
\hline
\end{tabular}

Table 7: Frequency of auditing Notes: One observation per subject per period. The 422 auditing requests encompass $100 \%$ of the observations.

\section{Conclusions}

The experiment shows that subjects did take steps to make communication truthful. Yet, contrary to Wilson and Sell (1997)'s conjecture, the ability to send messages that amounted to binding promises did not improve the effectiveness of communication due to an exploitative use by defectors. Defectors "held up" those who pledged cooperation, which ultimately lowered the value of communicating cooperative intentions as a mean to achieve a cooperative outcome. Such result might not survive if we removed the option of sending a neutral message. On the one hand, this would eliminate the possibility to hide the intention to hold-up cooperators by sending a non-committal message. And on the other, it would essentially force every individual to 
commit to either defection or cooperation. Therefore, it is hard to tell whether cooperation would increase or decrease in this case. Future research can shed some light on this. 


\section{References}

Aumann, R. (1990), "Nash Equilibria are not Self-enforcing." in Economic Decision Making:

Games, Econometrics and Optimization (J.J. Gabszewicz; J.F. Richard and L.A. Wolsey Eds.)

Elsevier, Amsterdam, New York.

Camera, G., and M. Casari (2009), "Cooperation among strangers under the shadow of the future." American Economic Review, 99(3), 979-1005.

Duffy, J. and N. Feltovich (2006), "Words, Deeds and Lies: Strategic Behavior in Games with Multiple Signals.” Review of Economic Studies, 73, 669-688.

Ellison, G. (1994), “Cooperation in the Prisoner's Dilemma with Anonymous Random Matching." Review of Economic Studies, 61, 567-588.

Farrell, J. and M. Rabin (1996), “Cheap talk.” Journal of Econ. Perspectives 10, 103-118.

Kandori, M. (1992), “Social Norms and Community Enforcement.” Review of Economic Studies, $59,63-80$.

Ostrom, E., J. Walker, and R. Gardner (1992), “Covenants With and Without a Sword: SelfGovernance is Possible.” American Political Science Review, 86, 404-417

Roth, A. E., and K. Murnighan (1978), "Equilibrium Behavior and Repeated Play of The Prisoner's Dilemma.” Journal of Mathematical Psychology, 17: 189-198.

Wilson, R. K., and J. Sell (1997), "Liar, Liar... Cheap Talk and Reputation in Repeated Public Goods Settings.” Journal of Conflict Resolution, 41 (5), 695-717. 


\section{Supporting Material \\ (not for publication)}

\section{Measuring cooperation}

The mean cooperation rate for economy $k=1, . ., n$ is measured by coding a cooperative action as 1 ( 0 otherwise). Define the action $a_{i t}{ }^{k}=0,1$ of subject $i=1, . .4$ in period $t=1, . ., T^{k}$ of the economy $k$; average cooperation in economy $k$ is $c_{k}=\frac{1}{4 \mathrm{~T}^{k}} \sum \sum a_{i t}^{k}$ between zero and one, and across economies is $c=\frac{1}{n} \sum_{k=1}^{n} c_{k}$. Thus, although economies have different length $T^{k}$, they are given equal weight in our measure $\mathrm{c}$ of average cooperation. In economy $k$ the coordination on cooperation rate is $c c_{k}=\frac{1}{T^{k}} \sum_{t=1}^{T^{k}} \prod_{i=1}^{4} a_{i t}^{k}$; the average across economies is $c c=\frac{1}{n} \sum_{k=1}^{n} c c_{k}$. The duration of each supergame 1 through 5 for each session is reported below:

\begin{tabular}{llcccccc}
\hline \hline \multicolumn{2}{l}{ Treatments } & $\mathbf{1}$ & $\mathbf{2}$ & $\mathbf{3}$ & $\mathbf{4}$ & $\mathbf{5}$ & Total \\
\hline \multirow{2}{*}{ Baseline } & Session 1 & 24 & 19 & 47 & 25 & 14 & 129 \\
& Session 2 & 13 & 11 & 7 & 41 & 53 & 125 \\
\multirow{2}{*}{ Pledge } & Session 1 & 47 & 2 & 10 & 3 & 13 & 75 \\
& Session 2 & 3 & 7 & 2 & 42 & 25 & 79
\end{tabular}




\section{Treatment effects on cooperation}

\begin{tabular}{|c|c|c|c|}
\hline & $\begin{array}{c}\text { [1] Average } \\
\text { cooperation } \\
\text { rates } \\
\text { Tobit regression }\end{array}$ & $\begin{array}{c}\text { [2] Average } \\
\text { cooperation in } \\
\text { period } 1 \\
\text { Logit regression, } \\
\text { marginal effects }\end{array}$ & $\begin{array}{l}\text { [3] Coordination on } \\
\text { cooperation } \\
\text { Tobit regression }\end{array}$ \\
\hline Pledge (dummy) & $\begin{array}{l}0.413 * * * \\
(0.143)\end{array}$ & $\begin{array}{c}0.099 \\
(0.102)\end{array}$ & $\begin{array}{l}0.612 * * \\
(0.276)\end{array}$ \\
\hline \multicolumn{4}{|l|}{ Cycle dummies } \\
\hline Cycle 2 & $\begin{array}{l}0.124 * * \\
(0.053)\end{array}$ & $\begin{array}{l}-0.073 \\
(0.081)\end{array}$ & $\begin{array}{c}0.318^{* * * *} \\
(0.014)\end{array}$ \\
\hline Cycle 3 & $\begin{array}{l}0.378^{* * * *} \\
(0.061)\end{array}$ & $\begin{array}{l}-0.011 \\
(0.031)\end{array}$ & $\begin{array}{c}0.511 * * * \\
(0.075)\end{array}$ \\
\hline Cycle 4 & $\begin{array}{l}0.456 * * * \\
(0.138)\end{array}$ & $\begin{array}{c}0.068 \\
(0.076)\end{array}$ & $\begin{array}{c}0.582 * * * \\
(0.139)\end{array}$ \\
\hline Cycle 5 & $\begin{array}{l}0.566^{* * * *} \\
(0.166)\end{array}$ & $\begin{array}{c}0.099 \\
(0.111)\end{array}$ & $\begin{array}{c}0.730 * * * \\
(0.216)\end{array}$ \\
\hline \multicolumn{4}{|l|}{ Cycle dummies x Pledge } \\
\hline Cycle 2 x Pledge & $\begin{array}{c}-0.510^{* * *} \\
(0.183)\end{array}$ & $\begin{array}{l}-0.186^{*} \\
(0.108)\end{array}$ & $\begin{array}{c}-1.217 * * * \\
(0.060)\end{array}$ \\
\hline Cycle 3 x Pledge & $\begin{array}{c}-0.531 * * * \\
(0.192)\end{array}$ & $\begin{array}{l}-0.152 \\
(0.111)\end{array}$ & $\begin{array}{c}-1.323 * * \\
(0.540)\end{array}$ \\
\hline Cycle 4 x Pledge & $\begin{array}{l}-0.441^{*} \\
(0.229)\end{array}$ & $\begin{array}{l}-0.178 \\
(0.124)\end{array}$ & $\begin{array}{c}-1.113 * * * \\
(0.307)\end{array}$ \\
\hline Cycle $5 \mathrm{x}$ Pledge & $\begin{array}{c}-0.786^{* * *} \\
(0.295)\end{array}$ & $\begin{array}{l}-0.228 \\
(0.161)\end{array}$ & $\begin{array}{c}-1.024 * * * \\
(0.326)\end{array}$ \\
\hline Length of the current cycle & $\begin{array}{l}-0.010 * * \\
(0.004)\end{array}$ & $\begin{array}{l}-0.002 \\
(0.002)\end{array}$ & $\begin{array}{l}-0.003 \\
(0.002)\end{array}$ \\
\hline Length of the previous cycle & $\begin{array}{l}0.008 * * * \\
(0.001)\end{array}$ & $\begin{array}{l}0.004 * * * \\
(0.001)\end{array}$ & $\begin{array}{c}0.012 * * * \\
(0.004)\end{array}$ \\
\hline Constant & $\begin{array}{l}0.434 * * * \\
(0.120)\end{array}$ & & $\begin{array}{c}-0.668 * * \\
(0.293)\end{array}$ \\
\hline$N$ & 400.000 & 400.000 & 100.000 \\
\hline Log-likelihood & -367.978 & -306.751 & -244.116 \\
\hline
\end{tabular}

Notes: * Standard errors in parentheses, * significant at 10\%; ** significant at $5 \%$;** significant at $1 \%$. Standard errors are robust for clustering at the session level. In models [1] and [2], the unit of observation is the subjects, in a cycle. In model [3] the unit of observation is the economy in a cycle.

\section{Table A1: treatment effects on cooperation}

Table A1, column [1] reports the results from a tobit regression that explains the individual choice to cooperate (1) or not (0) using treatment dummies and other regressors that control for fixed effects (cycles, duration of the current and previous cycle). The availability of structured communication in the Pledge treatment is associated with an initial increase in the cooperation rate for the representative subject, but this effect vanishes in later cycles: cooperation rates significantly increase in the Baseline, but not in the Pledge treatment. The other columns consider cooperation in period 1 and a measure of coordination on cooperation. 


\section{Effect on cooperation of manifesting a cooperative intention}

\begin{tabular}{ll}
\hline $\begin{array}{l}\text { Dependent variable: cooperation } \\
\text { marginal effects from probit regressions }\end{array}$ & Pledge \\
\hline msg_sent (=1 if subject Sent cooperative message Y) & $0.558^{* * *}$ \\
msg_observed (=1 if subject observed 2 or 3 & $(0.043)$ \\
cooperative messages) & $0.088^{*}$ \\
& $(0.047)$ \\
(msg_sent.) x (msg_observed) & $0.313^{* * *}$ \\
& $(0.035)$ \\
cycle 2 & $-0.135^{*}$ \\
& $(0.072)$ \\
cycle 3 & 0.001 \\
& $(0.007)$ \\
cycle 4 & $-0.221^{* *}$ \\
cycle 5 & $(0.105)$ \\
& $0.028^{* * *}$ \\
Duration of previous cycle & $(0.005)$ \\
communication $(1$ in periods $1,5,9, .)$. & $-0.004^{* *}$ \\
& $(0.002)$ \\
Pseudo R-squared & $0.087^{* *}$ \\
& $(0.040)$ \\
\hline
\end{tabular}

\section{Table A2: Effect of signaling cooperative intentions on cooperation}

Notes: We regress the binary choice of cooperation/defection on three main regressors, as well as standard control variables (duration of the previous cycle, cycle and period dummies, individual fixed effects, and a dummy for periods in which communication was possible). The first regressor is a dummy that takes value 1 when the subject signaled her intention to cooperate (i.e., sent a message Y "for herself") and 0 otherwise. The second regressor is also a dummy, which takes value 1 in periods when communication was possible and the subject observed at least two cooperative messages from others. The third regressor is an interaction term between the first two. Standard errors robust for clustering at the session level are reported in parentheses. ${ }^{*}$ significant at $10 \%$; ** significant at $5 \%$; ** significant at $1 \%$. Individual fixed effects.

In the probit regression reported in Table A2, we explain the cooperation actions $(0=$ defect, $1=$ cooperate) using as independent variables the messages made public in the economy, controlling for period effects, cycle order and duration. 


\section{Instructions (Pledge treatment)}

\section{$\underline{\text { Overview }}$}

This is an experiment in decision-making. Purdue University has provided funds for this research. The instructions are simple. If you follow them carefully and make good decisions, you can earn an appreciable amount of money. These earnings will be paid to you in cash at the end of the experiment.

We ask that you not talk with one another for the duration of the experiment. Please turn off your cell-phones. Do not use e-mail.

During the course of this experiment, you will be called upon to make decisions in several periods. The experiment is divided into five sequences of periods and each sequence is referred to as a cycle.

- $\quad$ At the beginning of a cycle, each participant in this room will be randomly assigned to a set.

- $\quad$ In each set there will be four persons.

- $\quad$ For the whole duration of a cycle, you will interact exclusively with the three other participants in that set and nobody else.

- $\quad$ You will never meet again these participants in the following cycles.

In each period of a cycle:

- In each period you will be matched to one other participant selected at random from the set you are assigned to. We will refer to this person as "your match."

- You will not be informed of the identity of your match. Hence, you do not know when you have already interacted with that person in previous periods of the same cycle.

- You and your match will interact according to the rules described in the upper portion of your screen. The rules will be explained in a moment.

- $\quad$ After each period you will be re-matched to a participant chosen at random from the set you are assigned to. There is one chance out of three that you will be matched with any given person in your set. 


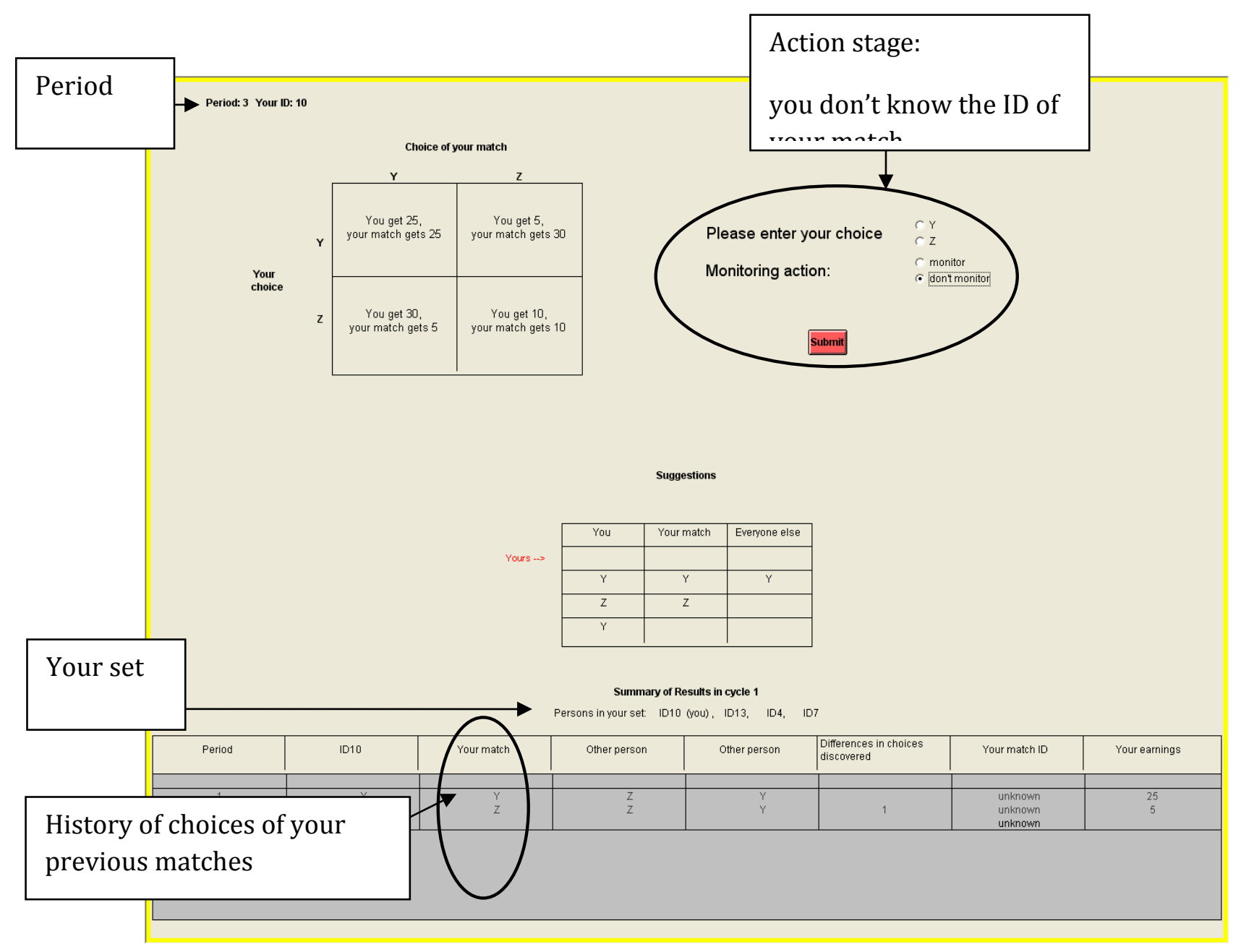

\section{$\underline{\text { Interaction rules }}$}

In a period you can make either of two choices, $\mathrm{Y}$ or $\mathrm{Z}$. In addition, you can "monitor" or "not monitor" the people in your set. The points you earn in this action stage depend upon both the choice you make and the choice made by others in that period. We now focus on the choice of either $\mathrm{Y}$ or $\mathrm{Z}$, by you and your match. Later we explain the "monitor" choice. As the payoff table on your screen (above) indicates, there are four possible outcomes:

1. If you and your match choose $\mathrm{Y}$ then: you both earn 25 points.

2. If you choose $\mathrm{Y}$ and your match chooses $\mathrm{Z}$ then: you earn $\mathbf{5}$ points and your match earns $\mathbf{3 0}$ points.

3. If you choose $\mathrm{Z}$ and your match chooses $\mathrm{Y}$ then: you earn $\mathbf{3 0}$ points and your match earns $\mathbf{5}$ points. 
4. If you both choose $\mathrm{Z}$ then: you both earn 10 points.

In each period you can also select either "monitor" or "not monitor." This choice will become clear in a moment once you have learnt about the suggestion stage. Through a suggestion you will be able to tell other people, without any commitment nor cost, if you suggest to choose $Y$ or $Z$.

A. If you select "monitor," you will pay a fee of 1 point.

The consequence is this: anyone in your set (including you) who made a choice $\mathrm{Y}$ or $\mathrm{Z}$ that is different than her suggestion $\mathrm{Y}$ or $\mathrm{Z}$ will lose 10 points.

Example: suppose this period you select to monitor. If someone in your set choose $\mathrm{Y}$ this period but had previously suggested $Z$, then she loses 10 points. Basically, your request to monitor compares the $\mathrm{Y} / \mathrm{Z}$ choices of everyone in your set with their individual $\mathrm{Y} / \mathrm{Z}$ suggestions. In the example, if someone suggests $\mathrm{Y}$ for herself and then does indeed choose $\mathrm{Y}$, she never lose points because of monitoring. Also, if someone makes no suggestion for herself, she never loses points because of monitoring.

As a result of monitoring either $0,1,2,3$, or 4 people may lose 10 points each.

B. If you select "not monitor," you will not pay any fee.

There are two important things to know.

First, even if you select "not monitor," someone else might monitor you. In that case, you lose 10 points if your $\mathrm{Y} / \mathrm{Z}$ choice is different than your suggestion for yourself.

Second, if more than one person selects to monitor, you still lose 10 points and not more.

To make one of the choices, click the button next to either Y or Z. You may change your mind at any time prior to clicking the "Submit" button by simply clicking on the button next to Y or Z. You are free to choose $\mathrm{Y}$ or $\mathrm{Z}$ in every period. In addition, to make the other choice, click the button next to either monitor or not monitor. You are free to choose monitor or not monitor in every period. When you are satisfied with both your $\mathrm{Y} / \mathrm{Z}$ choice and your monitoring action, click the "Submit" button. 


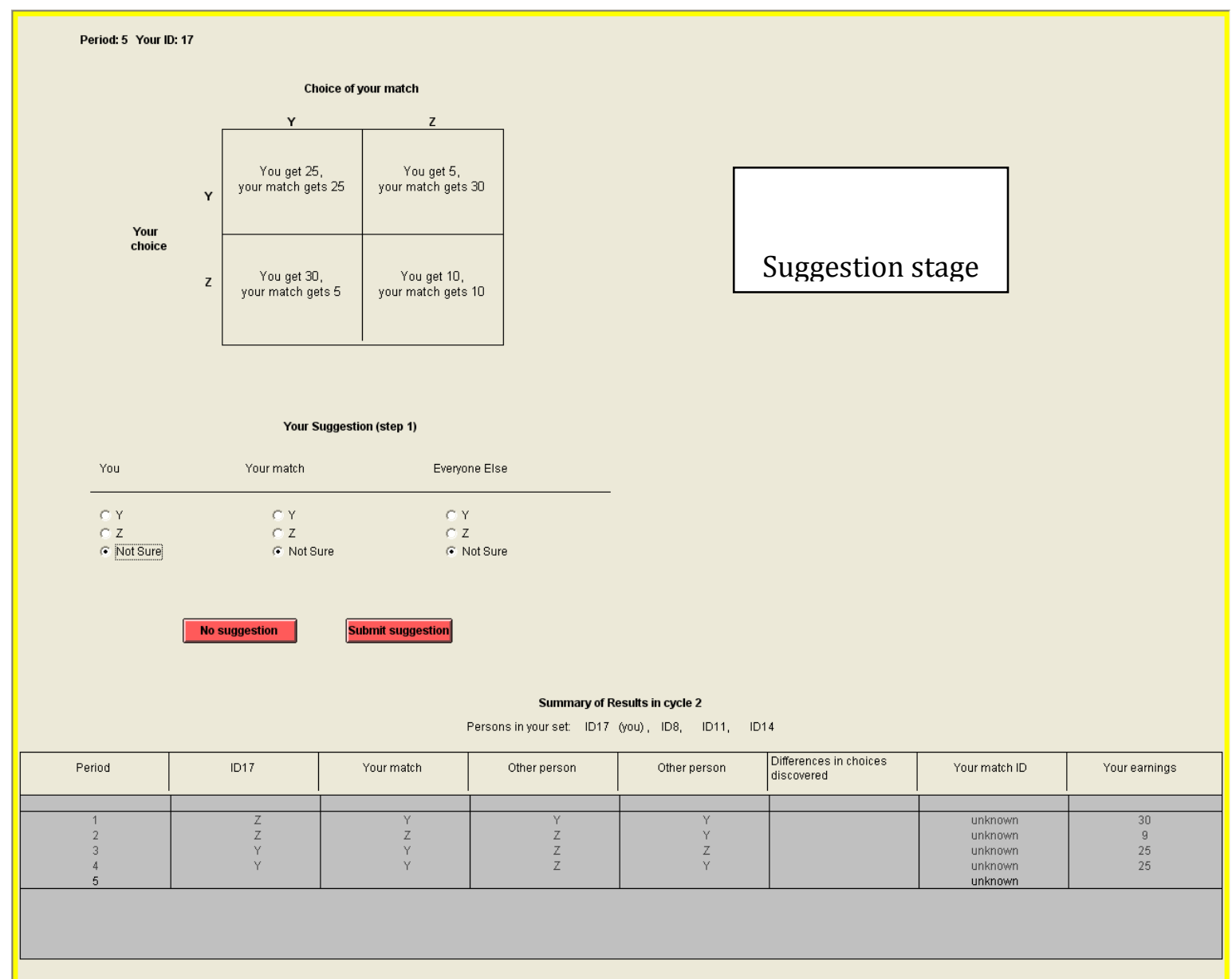

In addition to the action stage described above, there will be a suggestion stage before period one and then every four periods. In the suggestion stage you will have an opportunity to exchange suggestions about choices with everyone in your set. You are free to skip the suggestion stage entirely by clicking the "No Suggestion" button.

The suggestion stage gives you the opportunity to suggest choice $\mathrm{Y}$ or $\mathrm{Z}$ for any person in your set. Suggestions concern choices for you, for your match, and for everyone else in your set. To share your suggestion, click the "Submit suggestion" button. Your suggestion is shared with everyone in your set. All suggestions from people in your set will be displayed in a table in the middle of the screen.

In the action stage, you are always free to choose $\mathrm{Y}$ or $\mathrm{Z}$ regardless of suggestions made by you or others in the suggestion stage. After all choices and suggestions for the period have been made, the results of the period will appear on your screen. 


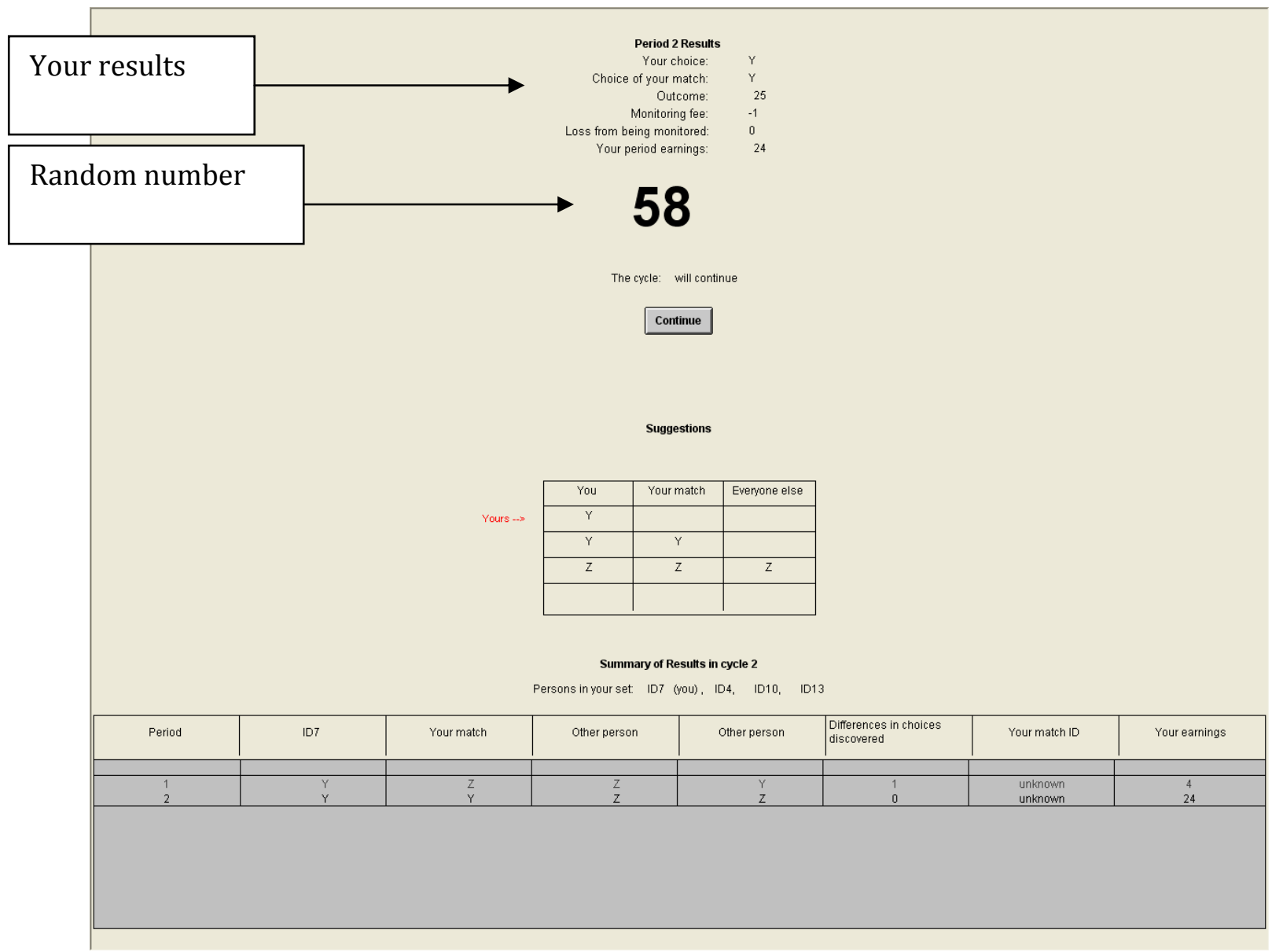

The result screen (above) will display the number of points you have earned for the period as well as the choices of all four persons in your set. The first column of the 'Summary of Results' table contains your past choices. The second column concerns the choices of your previous matches. The third and fourth columns list the choices of the other two persons in your set. Notice that choices in the column labeled "Your match" were most likely made by different persons in different periods. The same can be said for the two columns labeled "Other person".

You will also learn the outcome from monitoring. If the "Differences in choices discovered" column is empty in a given period then you know that no one selected "monitor." Instead, if a number 0 , $1,2,3$, or 4 is present, then you know that someone chose "monitor," and the number indicates how many people made choices that differed from their suggestions. Keep in mind that the way people are ordered in the Summary of Results table is generally different than in the Suggestion table. Please record your results for the period on your RECORD SHEET under the appropriate headings.

At this stage a ball will be drawn from an urn containing one hundred balls numbered from 1 to 100. Each ball is equally likely to be selected. The computer program will randomly draw a ball and show the number on the result screen (above). If this random number is less than or equal to 95, then the cycle will continue into the next period. If this number is greater than 95 , then the cycle ends. Therefore, after 
each period there is a $95 \%$ chance that there will be another period of interactions in the cycle and a $5 \%$ chance that the cycle will end.

Suppose that a number less than or equal to 95 has been drawn. Then you press the "Continue" button to proceed. You will face the same decisional situation as in the previous period, but with a person selected at random from the set of participants you were assigned to. Remember that there are four participants in each set.

Before making your choice, you may review all the outcomes in previous periods of the cycle by scrolling down the "Summary of Results" table. The table shows your past choices and the past choices of all persons in your set. You then choose either Y or Z and either "monitor" or "not monitor." All choices for this period are recorded and added to the Summary of Results table in the lower portion of your screen. You then record the outcome and your point earnings for the period.

If the number drawn is greater than 95 then the cycle ends. When a cycle ends, you will be notified in a new screen. There will be a total of five cycles. The rules in the following cycles are the same as in the first, but you will interact with different persons. More precisely, after each cycle, new sets of persons will be formed. This assignment does not depend on actual choices. A participant will never interact with a person for more than one cycle.

\section{Earnings}

The points you earned in each period are added up. For every 10 points that you earn you will receive 13 cents $(\$ .13)$. Therefore, the more points you earn the more money you earn. You will be paid your earnings in cash and in private at the end of today's session. 


\section{$\underline{\text { Final Comments }}$}

First, do not discuss your choices or your results with anyone at any time during the experiment.

Second, your ID\# is private. Do not reveal it to anyone.

Third, since there is a $95 \%$ chance that at the end of a period the cycle will continue, you can expect, on average, to interact for 20 periods in a given cycle. However, since the stopping decision is made randomly, some cycles may be much longer than 20 periods and some others may be much shorter.

Fourth, remember that after each period you will be matched randomly to someone in the set you were assigned to. As there are four people in the set, the probability of you being matched with the same person in two consecutive periods of a cycle is $1 / 3$. You are not told the identity of your match.

Fifth, before period one and then every four periods there will be a suggestion stage. In that stage you have an opportunity to suggest choices to people in your set. In the action stage everyone is free to choose $\mathrm{Y}$ or $\mathrm{Z}$ independently from any suggestion and everyone has an opportunity to "monitor" others in the set.

Sixth, the rules are the same in all five cycles. After a cycle, you will never meet again the same participants.

Questions?

Now is the time for questions. Does anyone have any questions before we begin? 
QUIZ

1. The total number of cycles is

2. You are at the beginning of the cycle. How many periods do you expect the cycle will last, on average?

3. You are in period 15 of the cycle. How many additional periods do you expect, on average?

4. The number of participants in the experiment (total in the room) is

5. In a given cycle with how many participants could you interact with (i.e. number of people in a set)?

6. If you select to monitor, how many participants do you actually monitor?

7. Other than your match, will you know at the end of the period the actions taken by people in your set?

8. Will you know at the end of the period the actions taken by participants outside your set?

9. Before choosing an action, will you know the ID of your match?

10. If ID 5 is in your set this cycle, is there any chance that ID 5 will be your match in future cycles?

11. How many points do you earn if both you and your match choose $\mathbf{Y}$ and nobody monitors?

12. In the action stage, you chose $\mathbf{Z}$ and "monitor." Your match chose $\mathbf{Y}$. How many points do you earn?

13. In the suggestion stage you suggested $Y$ for yourself. In the action stage, you chose $\mathbf{Z}$ and "not monitor." Your match chose $\mathbf{Y}$ and "monitor." How many points do you earn?

12. If the experiment lasts 100 periods and everybody always chooses $\mathbf{Y}$ and nobody monitors (see question 11), how many dollars are you going to earn?

15. How many points do you earn if you and your match choose $\mathbf{Z}$ and nobody monitors?

16. If the experiment lasts 100 periods and everybody always chooses $\mathbf{Z}$ and nobody monitors (see question 15), how many dollars are you going to earn? 


\section{2}

\section{Economic Science Institute Working Papers}

12-26 Schniter, E., Shields, T. and Dickhaut, J. Ageism \& Cooperation.

12-25 Gjerstad, S. and Smith, V. Balance Sheet Crises: Causes, Consequences and Responses.

12-24 Gómez-Miñambres, J., Corgnet, B. and Hernán-Gonzalez, R. Goal Setting and Monetary Incentives: When Large Stakes Are Not Enough.

12-23 Clots-Figueras, I., Hernán González, R., and Kujal, P. Asymmetry and Deception in the Investment Game.

12-22 Dechenaux, E., Kovenock, D. and Sheremeta, R. A Survey of Experimental Research on Contests, All-Pay Auctions and Tournaments.

12-21 Rubin, J. and Sheremeta, R. Principal-Agent Settings with Random Shocks.

12-20 Gómez-Miñambres, J. and Schniter, E. Menu-Dependent Emotions and Self-Control.

12-19 Schniter, E., Sheremeta, R., and Sznycer, D. Building and Rebuilding Trust with Promises and Apologies.

12-18 Shields, T. and Xin, B. Higher-order Beliefs in Simple Trading Models.

12-17 Pfeiffer, G. and Shields, T. Performance-Based Compensation and Firm Value: Experimental evidence.

12-16 Kimbrough, E. and Sheremeta, R. Why Can't We Be Friends? Entitlements, bargaining, and conflict.

12-15 Mago, S., Savikhin, A., and Sheremeta, R. Facing Your Opponents: Social identification and information feedback in contests.

12-14 McCarter, M., Kopelman, S., Turk, T. and Ybarra, C. Too Many Cooks Spoil the Broth: How the tragedy of the anticommons emerges in organizations.

12-13 Chowdhury, S., Sheremeta, R. and Turocy, T. Overdissipation and Convergence in Rent-seeking Experiments: Cost structure and prize allocation rules.

12-12 Bodsky, R., Donato, D., James, K. and Porter, D. Experimental Evidence on the Properties of the California's Cap and Trade Price Containment Reserve.

12-11 Branas-Garza, P., Espin, A. and Exadaktylos, F. Students, Volunteers and Subjects: Experiments on social preferences.

12-10 Klose, B. and Kovenock, D. Extremism Drives Out Moderation. 
12-09 Buchanan, J. and Wilson, B. An Experiment on Protecting Intellectual Property.

12-08 Buchanan, J., Gjerstad, S. and Porter, D. Information Effects in Multi-Unit Dutch Auctions.

12-07 Price, C. and Sheremeta, R. Endowment Origin, Demographic Effects and Individual Preferences in Contests.

12-06 Magoa, S. and Sheremeta, R. Multi-Battle Contests: An experimental study.

12-05 Sheremeta, R. and Shields, T. Do Liars Believe? Beliefs and Other-Regarding Preferences in Sender-Receiver Games.

12-04 Sheremeta, R., Masters, W. and Cason. T. Winner-Take-All and Proportional-Prize Contests: Theory and experimental results.

12-03 Buchanan, J., Gjerstad, S. and Smith, V. There's No Place Like Home.

12-02 Corgnet, B. and Rodriguez-Lara, I. Are you a Good Employee or Simply a Good Guy? Influence Costs and Contract Design.

12-01 Kimbrough, E. and Sheremeta, R. Side-Payments and the Costs of Conflict.

\section{1}

11-20 Cason, T., Savikhin, A. and Sheremeta, R. Behavioral Spillovers in Coordination Games.

11-19 Munro, D. and Rassenti, S. Combinatorial Clock Auctions: Price direction and performance.

11-18 Schniter, E., Sheremeta, R., and Sznycer, D. Restoring Damaged Trust with Promises, Atonement and Apology.

11-17 Brañas-Garza, P., and Proestakis, A. Self-discrimination: A field experiment on obesity.

11-16 Brañas-Garza, P., Bucheli, M., Paz Espinosa, M., and García-Muñoz, T. Moral Cleansing and Moral Licenses: Experimental evidence.

11-15 Caginalp, G., Porter, D., and Hao, L. Asset Market Reactions to News: An experimental study.

11-14 Benito, J., Branas-Garz, P., Penelope Hernandez, P., and Sanchis Llopis, J. Strategic Behavior in Schelling Dynamics: A new result and experimental evidence.

11-13 Chui, M., Porter, D., Rassenti, S. and Smith, V. The Effect of Bidding Information in Ascending Auctions.

11-12 Schniter, E., Sheremeta, R. and Shields, T. Conflicted Minds: Recalibrational emotions following trust-based interaction. 
11-11 Pedro Rey-Biel, P., Sheremeta, R. and Uler, N. (Bad) Luck or (Lack of) Effort?: Comparing social sharing norms between US and Europe.

11-10 Deck, C., Porter, D., and Smith, V. Double Bubbles in Assets Markets with Multiple Generations.

11-09 Kimbrough, E., Sheremeta, R., and Shields, T. Resolving Conflicts by a Random Device.

11-08 Brañas-Garza, P., García-Muñoz, T., and Hernan, R. Cognitive effort in the Beauty Contest Game.

11-07 Grether, D., Porter, D., and Shum, M. Intimidation or Impatience? Jump Bidding in On-line Ascending Automobile Auctions.

11-06 Rietz, T., Schniter, E., Sheremeta, R., and Shields, T. Trust, Reciprocity and Rules.

11-05 Corgnet, B., Hernan-Gonzalez, R., and Rassenti, S. Real Effort, Real Leisure and Real-time Supervision: Incentives and peer pressure in virtual organizations.

11-04 Corgnet, B. and Hernán-González R. Don’t Ask Me If You Will Not Listen: The dilemma of participative decision making.

11-03 Rietz, T., Sheremeta, R., Shields, T., and Smith, V. Transparency, Efficiency and the Distribution of Economic Welfare in Pass-Through Investment Trust Games.

11-02 Corgnet, B., Kujal, P. and Porter, D. The Effect of Reliability, Content and Timing of Public Announcements on Asset Trading Behavior.

11-01 Corgnet, B., Kujal, P. and Porter, D. Reaction to Public Information in Markets: How much does ambiguity matter?

\section{0}

10-23 Sheremeta, R. Perfect-Substitutes, Best-Shot, and Weakest-Link Contests between Groups.

10-22 Mago, S., Sheremeta, R., and Yates, A. Best-of-Three Contests: Experimental evidence.

10-21 Kimbrough, E. and Sheremeta, R. Make Him an Offer He Can't Refuse: Avoiding conflicts through side payments.

10-20 Savikhim, A. and Sheremeta, R. Visibility of Contributions and Cost of Inflation: An experiment on public goods.

10-19 Sheremeta, R. and Shields, T. Do Investors Trust or Simply Gamble?

10-18 Deck, C. and Sheremeta, R. Fight or Flight? Defending Against Sequential Attacks in the Game of Siege.

10-17 Deck, C., Lin, S. and Porter, D. Affecting Policy by Manipulating Prediction Markets:

Experimental evidence. 
10-16 Deck, C. and Kimbrough, E. Can Markets Save Lives? An Experimental Investigation of a Market for Organ Donations.

10-15 Deck, C., Lee, J. and Reyes, J. Personality and the Consistency of Risk Taking Behavior: Experimental evidence.

10-14 Deck, C. and Nikiforakis, N. Perfect and Imperfect Real-Time Monitoring in a Minimum-Effort Game.

10-13 Deck, C. and Gu, J. Price Increasing Competition? Experimental Evidence.

10-12 Kovenock, D., Roberson, B., and Sheremeta, R. The Attack and Defense of Weakest-Link Networks.

10-11 Wilson, B., Jaworski, T., Schurter, K. and Smyth, A. An Experimental Economic History of Whalers' Rules of Capture.

10-10 DeScioli, P. and Wilson, B. Mine and Thine: The territorial foundations of human property.

10-09 Cason, T., Masters, W. and Sheremeta, R. Entry into Winner-Take-All and Proportional-Prize Contests: An experimental study.

10-08 Savikhin, A. and Sheremeta, R. Simultaneous Decision-Making in Competitive and Cooperative Environments.

10-07 Chowdhury, S. and Sheremeta, R. A generalized Tullock contest.

10-06 Chowdhury, S. and Sheremeta, R. The Equivalence of Contests.

10-05 Shields, T. Do Analysts Tell the Truth? Do Shareholders Listen? An Experimental Study of Analysts' Forecasts and Shareholder Reaction.

10-04 Lin, S. and Rassenti, S. Are Under- and Over-reaction the Same Matter? A Price Inertia based Account.

10-03 Lin, S. Gradual Information Diffusion and Asset Price Momentum.

10-02 Gjerstad, S. and Smith, V. Household Expenditure Cycles and Economic Cycles, 1920 - 2010.

10-01 Dickhaut, J., Lin, S., Porter, D. and Smith, V. Durability, Re-trading and Market Performance.

2009

09-11 Hazlett, T., Porter, D., and Smith, V. Radio Spectrum and the Disruptive Clarity OF Ronald Coase.

09-10 Sheremeta, R. Expenditures and Information Disclosure in Two-Stage Political Contests.

09-09 Sheremeta, R. and Zhang, J. Can Groups Solve the Problem of Over-Bidding in Contests? 
09-08 Sheremeta, R. and Zhang, J. Multi-Level Trust Game with "Insider" Communication.

09-07 Price, C. and Sheremeta, R. Endowment Effects in Contests.

09-06 Cason, T., Savikhin, A. and Sheremeta, R. Cooperation Spillovers in Coordination Games.

09-05 Sheremeta, R. Contest Design: An experimental investigation.

09-04 Sheremeta, R. Experimental Comparison of Multi-Stage and One-Stage Contests.

09-03 Smith, A., Skarbek, D., and Wilson, B. Anarchy, Groups, and Conflict: An experiment on the emergence of protective associations.

09-02 Jaworski, T. and Wilson, B. Go West Young Man: Self-selection and endogenous property rights.

09-01 Gjerstad, S. Housing Market Price Tier Movements in an Expansion and Collapse.

\section{8}

08-09 Dickhaut, J., Houser, D., Aimone, J., Tila, D. and Johnson, C. High Stakes Behavior with Low Payoffs: Inducing preferences with Holt-Laury gambles.

08-08 Stecher, J., Shields, T. and Dickhaut, J. Generating Ambiguity in the Laboratory.

08-07 Stecher, J., Lunawat, R., Pronin, K. and Dickhaut, J. Decision Making and Trade without Probabilities.

08-06 Dickhaut, J., Lungu, O., Smith, V., Xin, B. and Rustichini, A. A Neuronal Mechanism of Choice.

08-05 Anctil, R., Dickhaut, J., Johnson, K., and Kanodia, C. Does Information Transparency Decrease Coordination Failure?

08-04 Tila, D. and Porter, D. Group Prediction in Information Markets With and Without Trading Information and Price Manipulation Incentives.

08-03 Thomas, C. and Wilson, B. Horizontal Product Differentiation in Auctions and Multilateral Negotiations.

08-02 Oprea, R., Wilson, B. and Zillante, A. War of Attrition: Evidence from a laboratory experiment on market exit.

08-01 Oprea, R., Porter, D., Hibbert, C., Hanson, R. and Tila, D. Can Manipulators Mislead Prediction Market Observers? 